\title{
Em torno da mesa do rei: artefatos, convivialidade e celebração no Rio de Janeiro joanino'
}

\section{Leila Mezan Algranti ${ }^{2}$}

RESUMO: Este artigo aborda um aspecto relevante do ritual das refeições na corte de D. João $\mathrm{VI}$, no Rio de Janeiro: a prataria de mesa. Isto é, objetos de luxo destinados a servir e a consumir os alimentos. Com base em um inventário de bens de mesa enviados do Rio de Janeiro para Lisboa junto com o monarca em seu retorno a Portugal, em 1821, este artigo procura refletir sobre as funções e possíveis usos desses objetos, assim como sobre a importância desse universo material para o funcionamento, representação e celebração da Casa Real portuguesa na sua nova sede. $\bigcirc$ artigo argumenta que a presença e o uso de baixelas de prata de serviço, mas também de grande aparato, nas refeições públicas da família real pode contribuir para se repensar a imagem de uma corte pobre e sem brilho recorrentemente reforçada na historiografia do período joanino.

PALAVRAS-CHAVE: Rituais de comensalidade. Prataria de mesa. História da alimentação.

ABSTRACT: This article discusses a specific issue of the royal dinner's rituals at the Court of Rio de Janeiro: the silver service: some luxury artifacts of different forms specially made to serve and consume food. Based on a inventory of these silver objects and also on a stock of table linen which were shipped to Lisbon, along with the royal family in 1821, The article intend to explore the functions and utilities of those objects at the table, as well as, analyze the importance of this material universe for the functioning, representation and celebration of the Portuguese Royal House in its new headquarters. The article argues that the use and even the exhibition of the banquet silver in public ceremonies may contribute to change a rather depreciative image of poverty the royal court in Brazil, which has being explored by the historiography for more than a hundred years.
1. A pesquisa realizada para este trabalho contou com o apoio do CNPq - Bolsa Produtividade. Sua primeira versão foi apresentada no VI Encontro Internacional de História Colonial, na mesa-redonda: "A casa, a cozinha e o quintal: práticas sociais e o trânsito de artefatos nos mundos ibero-americanos (séculos XVII-XIX), Salvador, 2016.

2. Docente do Instituto de Filosofia e Ciências Humanas da Universidade Estadual de Campinas. E-mail: <algranti@unicamp.br>.

KEYWORDS: Dinner's rituals. Banquet silver. Food history. 
3. D'Orey (1999, p. 6).

4. Entre os vários estudos disponíveis, ver, por exemplo, Arminjon; Saule (2004), Strong (2004, p. 113-228), Camporesi (1996), Pérez-Samper (1997).

5. Ver sobre $o$ assunto alguns estudos abrangentes em termos de abordagens e períodos históricos: Buescu; Felismino (2011), Pereira (2007). A baixela de prata de D. José I, por sua vez, recebeu atenção especial da historiografia, como se verá ao longo do presente artigo.

6. Inventario da Prata, e Roupa e mais trem pertencente à Mantearia, de Sua Magestade, q veio do Ryo de Janeiro. 1821. Arquivo Nacional da Torre do Tombo (ANTT), fundo Casa Real, Cx. 2986, f. 60 e ss, doravante citado como Inventario (1821). Sobre a Casa Real de D. João VI, no Brasil, da qual participavam também os setores dedicados à mesa, tais como a Cozinha, a Mantearia e a Ucharia, ver Castro (2016, p. 177-190), Andrade (2010).

7. De acordo com Raphael Bluteau, a mantearia ou "mantieiria é a casa em que se recolhem a prata e mais cousas concernentes ao ofício de mantieiro", ou manteeiro, que seria o responsável pela mantearia. Ele tinha sob suas ordens os moços da prata, responsáveis pelo recebimento $\mathrm{e}$ entrega da prata em serviço e da roupa de mesa. Bluteau $(1728$, v. 5 , p. 301).

8. Para uma análise das diferentes tipologias dos objetos de mesa em prata disponíveis no Setecentos português, ver Sousa (2002, p. 11-46).
Introdução

Em 26 de abril de 1821, após doze anos de estadia no Rio de Janeiro, iniciava-se a viagem de regresso de D. João VI a Portugal a fim de, mais uma vez, preservar sua Coroa e domínios. A partida da Corte foi precedida de muitas indecisões políticas e de intensos preparativos de ordem prática, da mesma forma como acontecera ao viajar para o Brasil, em 1807. Naquela ocasião, em meio aos riscos de invasão do Exército napoleônico, foi necessário acomodar nas embarcações não só os ilustres passageiros, mas também um conjunto imenso e variado de "coisas" destinadas ao uso particular de seus proprietários, bem como da Casa Real.

Entre os objetos embarcados, é interessante destacar neste estudo aqueles ligados a um componente importante no ritual das refeições das elites: a baixela de prata, ou seja, artefatos nos quais os alimentos eram servidos e consumidos, os quais compunham, juntamente com os protocolos de etiqueta, o serviço de mesa na Corte joanina. "Objeto de estudos aprofundados tanto do ponto de vista artístico como econômico e sociológico", conforme destacou Leonor d'Orey, ${ }^{3}$ pode-se dizer que o serviço de mesa tem se constituído, nas últimas décadas, em uma abordagem recorrente na história da alimentação, a qual reforça a tradição historiográfica dos estudos sobre o cotidiano e a vida privada. No que concerne à época moderna, as investigações em torno dessa temática vinculam-se especialmente ao estudo da vida de corte europeia e revelam aspectos essenciais da história do gosto, do consumo e da comensalidade em tais espaços. ${ }^{4}$ Os rituais da Monarquia portuguesa ligados ao cerimonial da mesa também têm recebido a atenção dos historiadores em estudos específicos. ${ }^{5}$

No caso do serviço de mesa de D. João VI, na América portuguesa - objetivo do presente estudo -, o tema é quase inexistente na historiografia brasileira, sendo que o ponto de partida de nossa análise será um documento bastante curioso, disponível no arquivo da Torre do Tombo, sobre a prata e a roupa de mesa que viajaram do Rio de Janeiro para Lisboa junto com a família real, em 1821.6

Trata-se de um inventário de objetos recebidos pelo manteeiro do Palácio da Ajuda, após a chegada da corte a Lisboa, o qual oferece poucas informações sobre os aspectos físicos dos mesmos, bem como sobre seu estado de conservação.7 A ausência de tais informações, como as marcas dos prateiros, o peso da prata, seus valores, ou a descrição de elementos decorativos, dificulta uma análise detalhada dos objetos em termos de suas características artísticas. Dados esses que seriam essenciais para aqueles que se dedicam ao estudo da ourivesaria ou das artes decorativas em geral. ${ }^{8} \bigcirc$ documento, no entanto, é rico em outros aspectos, uma vez que nos permite refletir sobre o consumo e a circulação dos artefatos de luxo no império luso-brasileiro e entre outros impérios - como é o caso da prataria de mesa -, além de fornecer indícios sobre os rituais das refeições 
na Corte joanina. É sobre esses dois aspectos, portanto, que gostaríamos de nos deter: de um lado atentar para a função e possíveis usos desses objetos, o que nos aproximará das formas de estar à mesa, isto é: do serviço, da etiqueta e até mesmo do consumo de certos alimentos - em suma, as artes da mesa. ${ }^{9}$ De outro, possibilita-nos pensar sobre os significados da posse de tais objetos para aqueles que os detinham, o que nos levará à questão da circulação desses artefatos, quer fosse por aquisição, herança ou sequestro de bens. Vejamos então mais de perto o inventário dos bens e alguns indícios históricos, materiais e sociais que o documento nos oferece sobre a mesa do rei.

$\bigcirc$ "torna-viagem" da prataria de mesa de D. João VI ${ }^{10}$

Conforme mencionado, um conjunto de peças de prata, roupas de mesa e artigos de copa, recém-chegados do Rio de Janeiro, viajou para Lisboa sob a incumbência de Joze de Britto, fiel da mantearia do rei, e foi entregue no pátio das cozinhas do Palácio da Ajuda a Joze Caetano Trigo, também funcionário do mesmo departamento da Casa Real, o qual realizou o registro das peças e o assinou por ordem de João Lourenço de Andrade que, por sua vez, recebeu todo o material em nome de Caetano Joze de Campos e Andrade Pinto, manteeiro da Casa Real, naquele momento. ${ }^{11}$

título do registro - Inventário da Prata, Roupa e mais trem pertencente à Mantearia de Sua Majestade que veio do Ryo de Janeiro ${ }^{12}$ - indica claramente que, ao retornar do Rio de Janeiro, D. João VI fez embarcar objetos de prata, os quais constituíam parte ou a totalidade de um serviço de mesa. $\bigcirc$ conjunto poderia conter elementos da famosa "baixela Germain", assim denominada por ter sido encomendada a François Germain por D. José I, em 1756, após o terremoto ter destruído a baixela de D. João $V$, fabricada pelo ourives de Luís XIV (Thomas Germain) e pai do prateiro de D. José.

A suposição de que poderia haver peças da baixela Germain de D. José I entre os artefatos registrados no inventário advém do fato de que há informações sobre seu transporte para o Brasil, bem como estudos referentes à divisão da mesma entre D. João Vl e D. Pedrol, antes do retorno do monarca a Portugal. ${ }^{13}$ Os bens que permaneceram no Brasil, por sua vez, teriam sido gravados com as insígnias imperiais e o monograma $\mathrm{P}^{\circ}$. De acordo com Leonor d'Orey,

considerando-se o que atualmente se encontra preservado desta baixela em Portugal, o lote do imperador do Brasil era menor, embora incluísse várias peças muito prestigiosas, as quais se encontram dispersas em coleções particulares e de museus estrangeiros, vendidas após a deposição de D. Pedro II. ${ }^{14}$

Sabe-se igualmente que entre a prataria de mesa de grande aparato pertencente à Casa Real havia peças da baixela dos duques de Aveiro, confiscada pela Coroa, após o atentado a D. José em 1759, ${ }^{15}$ assim como peças denominadas
9. As artes da mesa envolvem objetos, hábitos e gestos relacionados à comensalidade.

10. Utiliza-se o termo "torna-viagem" porque se entende que parte das peças do inventário analisado seria de objetos que acompanharam D. João VI na viagem de 1808 ao Brasil ou pertenciam à Família Real, tendo sido enviados de Portugal posteriormente. Se alguma dessas peças foi por ventura confeccionada na América portuguesa, essa pode também ter sido elaborada com matéria-prima de desmanche de peças estrangeiras, prática muito comum na época.

11. Sobre o assunto, ver Jar$\operatorname{dim}$ (2012).

12. Inventario (1821).

13. D'Orey (1999, p. 150), Jardim (2002, p. 181-209).

14. D'Orey (1999, p. 150).

15. Silva (2012, p. 69). As peças remanescentes dessa baixela - em grande parte originárias da parte que coube a D. João VI - encontram-se hoje sob a guarda dos museus Nacional de Arte Antiga e do Palácio da Ajuda, em Lisboa. 
16. Santos (2009).

17. Souza (2002, p. 11).

18. Silva (2012, p. 70).

19. Segundo especialistas, a prata usada no Brasil vinha do México ou das minas de Potosí. Era comum também usar-se "prata velha" para a confecção de peças novas em estilos mais recentes. Rosa (2007, p. 403-404).

20. Duarte (2005, p. 104).

21. Correia (2011, p. 167168). "avulsas". Por outro lado, "as baixelas para D. Pedro I foram encomendadas às famosas casas francesas", embora a técnica dos ourives radicados no Brasil fosse excelente, como apontou Francisco Marques dos Santos. Segundo o mesmo autor, muitas dessas peças emigraram, mas algumas voltaram. ${ }^{16}$

Havia, portanto, na corte no Rio de Janeiro, mais de um serviço de mesa em prata, sendo que um conjunto significativo dessas peças atravessou - Atlântico pelo menos duas vezes, a exemplo do que se sucedeu com a Família Real. Além disso, vários desses objetos foram possivelmente fabricados na França e na Inglaterra, uma vez que os prateiros portugueses nem sempre eram considerados, na época, suficientemente habilidosos para agradar o sofisticado gosto da alta nobreza portuguesa, consumidora de produtos de luxo importados não só de outros países da Europa, como do Oriente. Embora, como apontou Gonçalo de Vasconcelos e Sousa, houvesse prateiros de renome em Portugal, fabricando artefatos de mesa e mesmo baixelas completas, cuja qualidade do trabalho "atingiu durante o século das Luzes um dos seus momentos mais importantes". ${ }^{17}$

De qualquer modo, a mesa da Casa Real e aquelas de outros membros das elites europeias e luso-brasileiras eram há muito tempo aparamentadas com artefatos de prata estrangeiros, bem como com porcelanas e vidros chineses, germânicos e franceses. Como bem apontou Nuno Vassallo e Silva, em seu estudo sobre a ourivesaria da mantearia da Casa de Aveiro, não é possível refletir sobre as baixelas de prata ou de porcelana usadas na mesa real sem levar em conta a conexão dessa indústria com as manufaturas europeias e orientais. ${ }^{18}$

Assim, é possível dizer que os objetos de luxo destinados ao serviço de mesa da Corte joanina, no Rio de Janeiro, resultavam de um circuito comercial e de comunicação que interligava diferentes impérios coloniais (português, inglês, francês), os quais se estendiam por três continentes: Europa, Ásia e América. No caso dos artefatos de prata que nos interessam comentar neste estudo, é provável que a matéria-prima utilizada fosse originária da América espanhola, tendo retornado ao mesmo continente após ter sido trabalhada por habilidosos artesãos franceses para uso e ostentação dos monarcas portugueses. ${ }^{19}$ Por outro lado, tais objetos indicam um movimento mais amplo de evolução do gosto e da maneira de viver dos membros da aristocracia europeia, que remonta ao final do século XVII, cuja etiqueta de mesa foi fixada na corte de Luís XIV. Como assinalou Marco Daniel Duarte, a alta sociedade quando se sentava à mesa "se quer aprisionar por regras de etiqueta rígida". ${ }^{20}$

Mesmo levando-se em conta que no final do século XVIII Portugal acompanhava o restante da Europa, adotando nos banquetes reais a porcelana de Meissen (louça da Saxônia) e a de Sèvres como alternativas às baixelas de prata, conforme esclareceu Cristina Neiva, ${ }^{21}$ a prataria de mesa continuava a representar a riqueza e o poder das famílias reais, haja vista não só a encomenda de D. José I a François Germain, cuja baixela foi produzida ao longo da segunda metade do século XVIII, como também o fato de esta ter sido dividida entre o 
monarca e seu primogênito, antes da partida de D. João VI para a Europa. Sinal de que as mesas dos reis não poderiam prescindir dos objetos de prata em algumas situações. ${ }^{22}$

Atentar, portanto, para a lista de objetos em prata que retornaram a Portugal com D. João VI e analisar sua tipologia e quantidades permitem-nos refletir sobre uma espécie de "geografia da mesa", isto é, como tais objetos seriam dispostos e utilizados. ${ }^{23}$ É possível comentar também suas possíveis funções e os tipos de alimentos oferecidos em tais objetos, além de permitir constatar a individualização dos utensílios em relação aos comensais, interpretando os gestos e o modo de comer dos mesmos. Trata-se de procurar ler o inventário dos objetos a partir de sua materialidade, a fim de captarmos sua dimensão social, buscando-se as relações entre os objetos e os indivíduos, assim como dos objetos entre si. Sem as imagens e informações detalhadas dos objetos, a beleza e a riqueza das peças só podem ser imaginadas, a ponto de o monarca desejar preservá-las, quer fosse por razões de colecionismo e entesouramento, quer devido a sua utilidade. Mas ambas, certamente, por representarem um símbolo da grandeza e da nobreza da Casa Real. ${ }^{24}$

Observa-se de imediato na lista de bens que chegaram do Rio de Janeiro que os objetos destinados à copa eram de cobre ou de bronze, enquanto os de mesa eram em prata. Um dado indicativo da separação dos dois espaços tanto em termos de funções destinadas à alimentação como de simbologia e hierarquia dos objetos no ambiente doméstico. Estes atestam algumas tarefas desempenhadas no espaço, como a preparação das frutas e dos doces, bem como de clarear o sal, fazer e distribuir o pão e as saladas, além de confeccionar e realizar as obras de decoração. A copa oferecia ainda suporte ao serviço de mesa. Na lista analisada, há diferentes tipos de objetos, como, por exemplo, cafeteiras de cobre com e sem torneiras, além de chocolateiras e chaleiras do mesmo material, assim como tachos, escumadeiras, frigideira de ferro para torrar café, caixas para conduzir a prata e as iguarias, tabuleiros sortidos, gral de pedra e bancos para arear facas. ${ }^{25}$

Quanto aos artefatos de mesa, os quais compõem a maior parte do inventário, para efeito de análise foram agrupados em quatro grandes categorias quanto à sua utilidade e função. Primeiramente, objetos para senvir alimentos sólidos e líquidos, tais como travessas, terrinas, bules, talheres e salvas. Em seguida, objetos para consumir os alimentos, como aqueles destinados a levar os alimentos à boca los talheres), bem como para distribuir as porções entre os comensais: os pratos de comer - chamados de pratos de guardanapo. Um terceiro conjunto de objetos variados, mas fundamentais para o serviço de mesa das elites, compreendia aqueles usados para a iluminação, para as práticas de higiene à mesa e para a decoração /castiçais, jarros, bacias e estatuetas). E, por fim, a roupa de mesa que constituía um item à parte, mas era também de responsabilidade da mantearia da Casa Real.

A qualidade e, especialmente, a quantidade dos objetos nos permitem pensar que estes poderiam ser utilizados em uma mesa servida à francesa - forma ainda predominante no período joanino -, na qual os alimentos eram oferecidos em duas ou três mesas sucessivas cobertas com travessas de alimentos de vários
22. Ao que tudo indica, o serviço de prata de D. José I (denominada de baixela Germain) foi a maior encomenda feita por uma corte estrangeira ao famoso prateiro francês e, de acordo com especialistas, "sem dúvida uma das maiores criações dos prateiros parisienses do período". D'Orey (1999b, p. 149).

23. O termo "geografia de mesa” é uma expressão usada por Duarte (2005, p. 104).

24. Para Bourdieu, os símbolos do poder (trajo, cetro etc.) são apenas capital simbólico objetivado. Para o autor, "o poder simbólico, como poder de constituir o dado pela enunciação, de fazer ver e fazer crer, é um poder quase mágico que permite obter o equivalente daquilo que é obtido pela força [...], graças ao efeito específico de mobilização, só se exerce se for reconhecido, quer dizer ignorado como arbitrário" (Bourdieu, 1989 , p. 14).

25. Inventario (1821, fl. 64). Ver sobre as atividades desenvolvidas na copa: Correia (2002, p. 148-160). 
26. Cobertas ou serviços eram a forma de oferecer os alimentos no serviço à francesa, o qual refletia, como destacou Roy Strong, "a preocupação do século XVII com a ordem, o equilíbrio, o bom gosto e a elegância" (2004, p. 198). Alguns pratos, como as sopas ou os assados, ocupavam o lugar de destaque na mesa e eram cercados de muitas outras iguarias. A simetria na disposição dos pratos era fundamental. A maior parte dos livros de cozinha entre o século XVII e início do XIX apresentava menus e planos de mesa para servirem de orientação.

27. Sobre os protocolos e serviço de mesa em Portugal no século XVIII, ver Algranti (2011, p. 244-259; 2010, p. 87-113).

28. O termo "flamenga" não consta do dicionário de Raphael Bluteau. Segundo Maria do Rosário Jardim, os documentos sugerem pratos medianos e pequenos, um pouco maiores do que o prato de comer. Na documentação consultada pela autora, poderia ser denominação para pratos ligeiramente côncavos e com tampas (2002, p. 208). No inventário que estamos analisando, tudo leva a crer serem recipientes para servir alimentos, porém, sem tampas, semelhantes às travessas.

29. A terrina oval é considerada uma influência francesa. Havia também terrinas redondas. Ambos os tipos eram geralmente acompanhados de suas tampas e travessas de apoio, enquanto as travessas poderiam adquirir diferentes formatos. Quanto às salvas, distinguiam-se entre salvas sem e com pé, podendo estas possuir três ou quatro pés. Sousa $(2002$, p. 13 e 17). tipos. Daí denominarem-se primeira, segunda e terceira "cobertas" ou serviços. ${ }^{26} \mathrm{~A}$ última coberta era de doces e de frutas, como indicam os livros de receitas do período e os protocolos a serem seguidos nos banquetes oficiais. ${ }^{27}$

serviço de mesa à francesa necessitava de um grande número de objetos do mesmo tipo, não só para dispor simultaneamente os vários alimentos de uma coberta, como para promover rapidamente a reposição das iguarias nas sucessivas mesas ou cobertas, como se observa, por exemplo, no inventário disponível e representado na Tabela 1 .

Tabela 1: Artefatos de mesa em prata enviados do Rio de Janeiro para a mantearia do Palácio da Ajuda de acordo com suas funções (1821)*

\begin{tabular}{|c|c|}
\hline $\begin{array}{c}\text { TIPOS DE OBJETOS DE ACORDO COM } \\
\text { SUAS FUNÇÕES }\end{array}$ & QUANTIDADES \\
\hline Para servir alimentos sólidos & 97 \\
\hline Para servir líquidos & 27 \\
\hline Talheres para servir & 32 \\
\hline Talheres de mesa & 1.296 (439 facas, 435 garfos e 422 colheres) \\
\hline Colherinhas para café e chá & 133 \\
\hline Pratos de guardanapo & 179 \\
\hline Para iluminação & 53 \\
\hline Para temperos & 06 \\
\hline Para higiene & 16 \\
\hline Salvas sortidas & 16 \\
\hline TOTAL & 1.855 \\
\hline
\end{tabular}

* Fonte: Inventario (1821)

A Tabela 2, por sua vez, referente aos objetos destinados a servir os alimentos, informa que no inventário das peças que viajaram do Rio de Janeiro para Lisboa havia um total de 97 travessas de diferentes tipos e tamanhos: como as "terrinas para sopas" 16 delas de "soubre comprido" com tampas e suas travessas); 62 "flamengas" 28 de tamanhos diferentes: grandes, médias e pequenas, além de pratos redondos e quadrados para servir assados, cozidos, saladas e legumes. Havia ainda 16 salvas "surtidas", que atendiam a uma grande diversidade de funções domésticas e não apenas à mesa. ${ }^{29}$ 
Tabela 2: Objetos de prata da Casa Real portuguesa para servir alimentos: tipologias e quantidades (enviados do Rio de Janeiro para Lisboa - 1821)*

\begin{tabular}{|c|c|c|}
\hline SÓLIDOS & LÍQUIDOS & TALHERES PARA SERVIR \\
\hline Flamengas 62 & Bules 04 & Collheres grandes de sopa 13 \\
\hline Terrinas 06 & Cafeteiras 10 & Colheres grandes para arroz 05 \\
\hline Pratos das terrinas 04 03 & Talheres de trinchar 03 \\
\hline Pratos travessos 17 & Chocolateiras 03 para açúcar 11 \\
\hline Pratos quadrados 08 & Leiteiras 10 \\
\hline TOTAL 92 & TOTAL 27 & TOTAL 32 \\
\hline
\end{tabular}

* Fonte: Inventario (1821)

No caso dos líquidos, observa-se na mesma Tabela 2 que havia mais cafeteiras (10) e leiteiras (10) em detrimento de bules para chá (4) e chocolateiras (3), o que pode sugerir uma preferência pelo consumo de café. O qual seria oferecido sem açúcar, sendo este disponível nos açucareiros e com colheres específicas. É de se notar também o registro simultâneo de 133 "colherinhas para café e chá", o que leva a crer se tratar de um mesmo utensílio com diferentes usos (vide Tabela 1).

Quanto aos "talheres para servir", estes parecem ser em número suficiente para um serviço à francesa composto de duas ou três cobertas, contendo sopas, assados e guisados, pois havia três jogos de trinchar carnes, embora nessa época as mesmas já fossem levadas à mesa cortadas. $\bigcirc$ documento menciona ainda treze conchas para servir sopa (colheres grandes) e cinco colheres para arroz - alimento que acompanhava frequentemente os guisados. Contudo, sempre é bom lembrar com Hans Ottomeyer que "o uso dos objetos determina sua forma". ${ }^{30}$ De tamanho ou aspectos físicos diferentes, são seus estilos e decoração que os constituem em conjuntos coerentes, informação esta que o inventário informa ocasionalmente, como no caso das flamengas: "duas flamengas grandes com seus filetes em roda; duas dittas mais piquenas; dezessete dittas mais piquenas e todas irmãs das dittas [sic]". Ou então: "sete pratos travessos com seus filetes; quatro pratos quadrados com seus filtes; dez pratos travessos todos lizos; quatro dittos travessos todos lizos [sic]". ${ }^{31}$ Tais especificações decorativas sugerem que os artefatos pertenciam a baixelas diferentes, enquanto seus tamanhos e formatos fornecem algumas possibilidades de uso: as peças maiores, por exemplo, poderiam ser utilizadas para servir os assados, e as menores, os entremeios (acompanhamentos) confeccionados à base de legumes e verduras, ovos e farinha, podendo conter também carnes.

30. Ottomeyer (2007, p. 230).

31. Inventario (1821). 
32. "Olha" é uma espécie de cozido, uma comida de origem espanhola feita de chouriço, carne, grão-de-bico, ervilhas e diversos temperos. De acordo com Bluteau, havia várias castas de olhas, como a olha podrida, cujo termo se originava de poderidas ou poderosas, pois era alimento de gente poderosa e também porque era preciso grandes panelas e recipientes para servi-las. Bluteau (1728, v. 6, p. 16).

33. Sousa (2002, p. 24).

34. Inventario (1821, fl. 63).
No serviço à francesa, os entremeios eram dispostos simetricamente ao longo da mesa de forma que todos os convivas pudessem se servir daqueles que mais os apetecessem. Nos menus eles são chamados, muitas vezes, de "pratinhos", possivelmente por serem oferecidos em pratos pequenos. As terrinas, além de serem indispensáveis para levar as sopas à mesa e conservarem seu conteúdo aquecido devido às tampas que possuíam, eram acompanhadas de um prato que ajudava a transportá-las e apoiá-las sobre a mesa, apesar de possuírem asas para esse fim. Dependendo do tamanho, as terrinas poderiam ser usadas também para servir os guisados ou "olhas", que necessitavam de um recipiente fundo para conter o molho ou caldo, embora nas baixelas com muitas peças houvesse objetos para esse fim denominados de "olhas" 32

Com relação aos objetos destinados ao consumo de alimentos, além de sua quantidade indicar claramente a individualização dos utensílios à mesa, pois havia 179 pratos de guardanapo e um número de facas, garfos e colheres praticamente equivalente (439 facas, 435 garfos, 422 colheres), o que nos leva a pensar na existência de um faqueiro propriamente dito (ou mais de um), com os três utensílios sendo utilizados juntos por cada comensal (vide Tabela 1). Como bem esclareceu Gonçalo de Vasconcelos e Sousa, "a segunda metade do século XVIII assiste em Portugal a uma explosão de uma diversidade de talheres", bem ilustrativa da complexidade que os hábitos à mesa alcançaram. Desde o início do mesmo século, contudo, "a colher, o garfo e a faca associam-se num talher individual, colocado junto ao prato de cada conviva e os cabos das três peças uniformizam-se através de uma decoração idêntica". ${ }^{33}$

$\bigcirc$ mesmo se pode dizer sobre o grande número de guardanapos de pano presente no documento analisado, o que permitiria largamente a troca de guardanapos individuais ao longo das diferentes cobertas em um banquete para muitos convidados. Aliás, no que se refere à roupa de mesa, os números são grandiosos, conforme atesta a Tabela 3. Observa-se um total de mais de 11.000 peças de pano divididas em dois lotes denominados "roupa fina" e "roupa grossa", as quais foram entregues junto com a prataria de mesa no Palácio da Ajuda. Tratase de 2.600 guardanapos e 819 "toalhas finas", devidamente especificadas ( 196 primeiras, 90 segundas, 553 terceiras). $\bigcirc$ que deduzimos tratar-se de toalhas para a primeira, segunda e terceira cobertas. A "roupa grossa" consistia em: 626 toalhas (96 grandes; 530 menores), 4.300 guardanapos e 2.800 "pannos de grossaria". Total de 11.145 artefatos de tecido. ${ }^{34}$

De acordo com a nomenclatura utilizada no registro dos bens inventariados, tudo indica que tais artefatos em pano eram destinados a diferentes espaços e momentos, uma vez que havia uma hierarquia rígida na composição das mesas da Casa Real, em função de quem se sentava em cada uma delas: a família real, a grande nobreza - que servia nos altos cargos da Casa Real - e todos os demais servidores dos diferentes setores das Casas do rei e da rainha. Além disso, parte da roupa grossa poderia ser para uso na copa. Observa-se, contudo, que guardanapos avulsos ou acompanhando as toalhas eram uma presença obrigatória na mesa da Casa Real. 
Tabela 3: Roupa de mesa enviada da Corte do Rio de Janeiro para a mantearia do Palácio da Ajuda em Lisboa (1821)*

\begin{tabular}{|c|c|}
\hline ROUPA FINA & ROUPA GROSSA \\
\hline $\begin{array}{c}\text { Toalhas } 819 \text { (196 primeiras; } 90 \text { segundas; } \\
553 \text { terceiras) }\end{array}$ & Toalhas 626 (96 grandes; 530 menores) \\
\hline $\begin{array}{c}\text { Guardanapos 2.600 } \\
\text { Toalhas de água às mãos } 400\end{array}$ & 27 \\
\hline TOTAL 3.819 & TOTAL 7.726 \\
\hline
\end{tabular}

* Fonte: Inventario (1821)

No que se refere à higiene à mesa, o hábito de água às mãos - tão próprio de um tempo não muito distante, no qual a nobreza ainda comia com as mãos permanece indicado no inventário de bens de mesa da Corte do Rio de Janeiro, por meio da presença de 8 bacias com seus jarros e 400 toalhas de água às mãos (vide Tabela 4). Sinal, talvez, de que tais artefatos ainda poderiam estar em uso, mas a frequência ou os significados dos gestos de lavar às mãos, ao longo das refeições, poderiam ter sofrido mudanças, de acordo com a etiqueta vigente e a adesão ao uso dos talheres.

Por fim, cabe destacar no documento analisado dois tipos de bens em prata discriminados na Tabela 4: aqueles destinados a conter produtos que destacavam o sabor dos alimentos, como os saleiros, os pimenteiros e as gallhetas para colocar azeite e vinagre, também registradas como galheteiros ou talher de galheta. Este último objeto consistia em uma estrutura ou base (cangalha) na qual se colocavam elementos distintos. Embora, desde o final do século XVIII (1780), o livro de cozinha de Lucas Rigaud, cozinheiro da nobreza, fizesse a apologia de uma nova culinária contendo menos condimentos, a fim de valorizar o sabor dos alimentos, os saleiros e especieiros continuavam presentes à mesa e eram geralmente objeto de decorações artísticas. ${ }^{35}$

A segunda modalidade de artefatos discriminados na Tabela 4, os "castiçaes de prata para luzes", aparecem em um total de 47 peças. $\bigcirc$ inventário não especifica os tipos de castiçais (com ou sem serpentinas), nem o número de braços dos mesmos. A única informação referente à sua materialidade, assim como no conjunto dos objetos do inventário, é o tipo de material do qual foram fabricados, no caso: a prata. Um metal que "não era extraído nos territórios da monarquia portuguesa, mas que possuía um papel destacado nos inventários pós mortem das casas aristocráticas portuguesas", como mostram os estudiosos do assunto. ${ }^{36}$ Ainda de acordo com o mesmo historiador, mais do que as joias, "eram as salvas, as baixelas e os talheres que constituíam sinais de riqueza nas grandes casas". ${ }^{37}$
35. Rigaud (1999), cozinheiro francês radicado em Portugal, havia cozinhado para a boa mesa palaciana europeia.

36. Monteiro (2011, p. 112). 37. Monteiro (2011, p. 112). 
Tabela 4: Artefatos de mesa em prata enviados da Corte do Rio de Janeiro para - Palácio da Ajuda em Lisboa: diferentes finalidades (1821)*

\begin{tabular}{|c|c|c|}
\hline HIGIENE & ILUMINAÇÃO & TEMPEROS \\
\hline Bacia para água às mãos 08 & Castiçais para luzes 47 & Galheteiro 02 \\
\hline Jarro para água às mãos 08 & Tesouras para luzes 03 & Saleiro 01 \\
\hline- & Pratinhos para as ditas 03 & Pimenteiro 01 \\
\hline TOTAL 16 & TOlher de galhetas 01 & TOTAL 32 \\
\hline
\end{tabular}

* Fonte: Inventario (1821)

38. Sobre o luxo conferido às mesas da aristocracia do litoral de Pernambuco e a presença de objetos de prata mencionados por Gilberto Freyre (2003, p. 12-14); sobre a prataria de mesa nos inventários do Rio de Janeiro, na segunda metade do século XVIII, Algranti (2016, p. 21-51).

39. Há referências a artífices portugueses trabalhando com prata na América portuguesa, desde o século XVII. Contudo, no século XVIII, quase a totalidade dos ourives na Bahia já era de naturais da terra. Sobre esse ofício e a correspondente legislação de proibição, na Bahia e no Rio de Janeiro, ver Rosa (2007, p. 403-406).

40. Pragmática (1760, p. 19-24).
Embora prata à mesa não fosse prerrogativa da realeza ou da alta nobreza, pois encontramos adornos e utensílios de mesa em prata nos inventários de comerciantes e de proprietários de terras no Rio de Janeiro, nos séculos XVII e XVIII, assim como em Olinda desde o século XVI, ${ }^{38}$ trata-se de uma matéria-prima que conferia não só valor aos objetos, mas também status a quem os possuísse. ${ }^{39}$

Uma vez que faltam dados para avaliarmos a qualidade da prata descrita, o que chama a atenção no inventário da Casa Real analisado é a grande quantidade de peças de mesa em prata, as quais expressam o luxo da mesa do rei. Na verdade, estas possibilitavam oferecer um tipo de serviço próprio dos rituais de comensalidade na Corte e nas casas dos grandes de Portugal. Todo esse luxo era, certamente, um fator de diferenciação social e sobre o qual a legislação portuguesa se posicionou repetidamente nas Leis Pragmáticas, desde a ldade Média. ${ }^{40}$ Denominadas também como leis suntuárias que visavam moderar - luxo e reprimir o excessivo fausto dos vassalos, eram calcadas, especialmente, na hierarquia e distinção existentes entre os indivíduos da sociedade. Tais leis expressavam a ideia de que o luxo deveria ser contido, a fim de não se arruinar a fazenda e os bons costumes dos indivíduos de posse e maior estado, uma vez que o gasto demasiado e a ostentação no vestuário, na mesa e na casa em geral acarretavam grandes prejuízos. Para aqueles de menor destaque social, no entanto, o luxo era vetado. Dessa forma, as leis suntuárias regulavam a posse de bens fabricados com materiais nobres, como o ouro, a prata e a seda, acomodando-os às presumíveis situações econômicas dos indivíduos. Ou seja, elas defendiam a necessidade de distinguir as pessoas em termos das aparências (vestuário inclusive), de acordo com seus títulos e empregos. Um elemento indicativo da importância que os objetos assumiam enquanto marcadores de posições na 
hierarquia social, algo a ser considerado quando se trata de analisar a comensalidade na corte joanina, na qual uma parte significativa dos utensílios de mesa eram fabricados com esse material nobre.

De acordo com o capítulo V da pragmática de 1749, expedida por D. João $V$, foi proibido "fazer de novo móveis alguns de casa em que entre prata, nem ouro fino ou falso, ou bordadura de qualquer sorte ou matéria, que seja; só poderiam ser douradas ou prateadas as molduras de espelhos, painéis, placas e pés dos bofetes". ${ }^{41}$ Outros capítulos da mesma Pragmática repetem a ideia em relação a roupas, coches e armas. No Capítulo XII, entretanto, a proibição e as penalidades se estendem aos artesãos e não mais apenas aos consumidores e proprietários que desrespeitassem a lei. Dessa forma, produzir artefatos em ouro e prata a quem não estivesse autorizado a possuílos era, igualmente, uma infração grave.

Por outro lado, os vários tipos de fontes consultadas evidenciam que uma refeição própria da realeza não poderia prescindir de um número mínimo de objetos - calculados de acordo com a quantidade dos comensais -, a fim de se cumprir o protocolo de serviço. Se a mantearia do palácio no qual o monarca se encontrava não possuísse todo o necessário para servi-lo adequadamente, os objetos poderiam ser deslocados de outros palácios. Trata-se de uma prática presente na Corte de D. João VI, assim como na de seus antecessores. ${ }^{42}$ Dispomos de registros, posteriores a 1821, que apontam nesse sentido e nos permitem dizer que os objetos de mesa na corte joanina circularam não só entre as diferentes localidades do império português - conforme já mencionado - mas entre os diferentes palácios de sua Majestade Fidelíssima. ${ }^{43} \bigcirc$ que vale, contudo, frisar, antes de nos determos nesse aspecto, é que os exemplos de circulação de artefatos dos quais dispomos se referem à prataria de mesa, embora na Corte joanina houvesse baixelas de outros materiais que atendiam a uma série de mudanças na forma de estar à mesa, a partir do século XVIII, quando se impôs maior sofisticação e valorização da etiqueta. ${ }^{44}$ Tal fato proporcionou, inclusive, o surgimento de novos utensílios para servir e consumir alimentos, os quais se tornaram imprescindíveis à aristocracia. ${ }^{45}$ Essa questão nos leva ao último ponto que gostaríamos de mencionar no presente estudo: a posse dos objetos de luxo.

A posse e a circulação de objetos de luxo no Império português: a "baixela de serviço" na Corte joanina do Rio de Janeiro

$\bigcirc$ desejo de possuir coisas e, principalmente, a necessidade de preservá-las são aspectos interessantíssimos da história do consumo de luxo na época moderna, os quais envolveram um grande número de artesãos, agentes comerciais e membros das elites europeias. Estes últimos, consumidores em potencial de um mercado em expansão ditado pela volatilidade da moda e exigências da vida em sociedade, mas também pelo conforto, riqueza e bem-estar que os produtos poderiam proporcionar.
41. Pragmática (1760, p. 20).

42. A título de exemplo, ver os preparativos que envolveram um deslocamento da corte de D. José I à Mafra: IAN/TT Ministério do Reino, livro 433, fl. 2, verso. Apud Algranti (2010, p. 87-116).

43. Inventario (1821, fls. 66-70).

44. Sobre as baixelas de porcelana de D. João VI, ver Braga (2011, p. 97).

45. O serviço à francesa reinou até o século XIX, quando cedeu lugar ao serviço à russa. Este visava evitar que os alimentos esfriassem, uma vez que no serviço à francesa os alimentos eram levados simultaneamente à mesa $\mathrm{e}$ ficavam expostos até o fim da coberta. No caso da nova proposta, apenas os pratos frios ficariam sobre a mesa, enquanto os quentes seriam oferecidos aos convivas individualmente. Flandrin (2002, p. 147-148). 
46. O Palácio de Queluz era a residência oficial da Família Real desde o incêndio que aconteceu na Ajuda, em 10 de novembro de 1794 .

47. Antônio Caldeira Pires, historiador do Palácio de Queluz, refere-se às ordens de D. João às vésperas da partida para o Brasil para se empacotar tudo o que fosse possível transportar: de tesouros das capelas reais a trajes de corte, além, é claro, de móveis e louças de seus palácios. Pires (1926, p. 308, v. 2).

48. Relação dos móveis que embarcaram para o Rio de Janeiro: "Relação de tudo o que vai do Real Palácio de Queluz para o Thesouro das Necessidades em fevereiro de 1809 , como consta dos caixotes que por seus números se declaram" apud Pires (1926, p. 315-326). O documento, citado por Caldeira Pires, é bastante detalhado, porém, como sucede outras vezes ao longo de seu livro, não há a informação sobre a origem dos documentos citados, o que torna difícil o acesso à informação. O catálogo da coleção de cerâmica do Palácio de Queluz endossa a informação retirada de Caldeira Pires: ver Ferro; Flores (2002, p. 9, nota 4).

49. Inventário de bens do Palácio do Palácio de Queluz em 1807 apud Pires (1926, p. 281-306, v. 2).

50. Pires (1926, p. 282, v. 2). Segundo esse autor, uma carta de João dos Santos, almoxarife do Palácio do Ramalhão, informava a princesa Carlota Joaquina, em 17 de outubro de 1808 , que toda a mobília desse palácio havia sido enviada para o Brasil, ao contrário do que sucedera com pertences de D. João e de outros senhores, que ficaram no cais de Lisboa. Pires (1926, p. 312, nota 1). inventário dos bens enviados da Corte do Rio de Janeiro para Lisboa em 1821, assim como documentos sobre a transferência da Família Real para o Brasil-especialmente aqueles referentes ao embarque de objetos do Palácio de Queluz -, oferece elementos para refletirmos sobre a posse e a circulação de alguns bens de luxo no Império português, entre os quais destacamos os objetos de mesa da Família Real. ${ }^{46}$ As referências sobre a viagem ao Brasil mencionam medidas a serem tomadas em relação a móveis, luminárias, relógios, obras de arte, tapeçarias e tecidos que deveriam partir para a América portuguesa. ${ }^{47} \bigcirc$ que não foi embarcado na ocasião, seguiu para a América em posteriores remessas, conforme inventário datado de 1809, contendo diversos objetos de uso pessoal e doméstico, entre os quais aparelhos de jantar, chá e café em porcelana. ${ }^{48}$ Tudo parece ter sido inventariado, após a partida da Família Real, pelo almoxarife do palácio de Queluz, João Crisóstomo, a fim de ser preservado e depois enviado para seus proprietários. ${ }^{49}$ Como disse Caldeira Pires, em sua História do Palácio de Queluz: "Ainda hoje se ignora parte das riquezas que foram enriquecer a formosa quinta da Boa Vista no Rio de Janeiro. Muitos dos móveis que foram do Palácio de Queluz e doutros, ainda hoje lá se conservam". ${ }^{50}$

A observação do autor pode conter muitos sentidos, mas, do ponto de vista da cultura material, confirma que havia um modo de vida e uma representação da realeza na qual os objetos eram extremamente importantes e investidos de significados. Como esclareceu Maravall, a arte barroca (entenda-se também as artes decorativas) "é uma glorificação dos poderes constituídos". 51 "É a arte dos regimes autoritários [...], que se impõe, ao expectador maravilhado e o transporta para fora de si; para que se esqueça de duvidar e questionar". 52

A correspondência que o almoxarife, situado em Lisboa, manteve com a Corte do Rio de Janeiro reforça a imagem de interesse e de preocupação de diferentes membros da Família Real com seus objetos pessoais, além dos cuidados especiais que João Crisóstomo dedicou ao patrimônio material régio (móvel e edificado) enquanto serviu à Casa Real. São ilustrativas de seu desempenho não só as remessas para o Brasil de artefatos de todo tipo, realizadas a pedido de D. Carlota Joaquina e princesas, como a supervisão de reparos nos palácios reais, antes do retorno de seus proprietários. ${ }^{53}$

No caso da mesa real na América portuguesa, cujos artefatos de prata viemos analisando neste estudo, observa-se que objetos de luxo confeccionados tanto em prata como em cerâmica não poderiam faltar. Estes, porém, não seriam os mesmos para todas as ocasiões, o que nos leva de volta ao inventário de bens enviados da corte do Rio de Janeiro em 1821 , pois, apesar de haver um número significativo de objetos em prata, próprio das grandes casas, não há qualquer menção a peças grandiosas - como os famosos e pesadíssimos centros de mesa (surtout) da baixela Germain. Tampouco há referências a candelabros com vários braços, decorados com sátiros esculpidos, ou tampas de terrinas ricamente adornadas com esculturas. Também não se observa na mesma lista de objetos os especieiros e molheiras de excepcional trabalho descritos pelos estudiosos desse 
serviço de mesa da Casa Real portuguesa, nem as figurinhas decorativas e tantas outras peças de requinte que caracterizam a baixela de D. José I. ${ }^{54}$

Outro dado que chama a atenção diz respeito ao fato de que os utensílios destinados à quarta coberta da baixela Germain (pratos e talheres de sobremesa) foram confeccionados em prata dourada. Ora, não há nada indicado em vermeil na lista das peças que foram enviadas do Rio de Janeiro, em 1821. Todas essas ausências informativas no inventário analisado levam a pensar que os artefatos elencados faziam parte de uma baixela "de serviço", de uso doméstico da Casa Real ou até mesmo destinada a cerimônias oficiais, mas que não seria uma "baixela de aparato", valiosíssima e encomendada para ser ostentada, como foi pensada e executada a baixela Germain, a qual foi vista em pouquíssimas cerimônias diplomáticas e celebrações régias, como casamentos e coroações. $\bigcirc$ inventário localizado indica que havia um grande número de peças em "prata lisa" ou com "seus filetes" que podiam ser usadas em um serviço de mesa para mais de cem pessoas, se fosse o caso. ${ }^{55}$ Tais objetos acompanharam a Família Real na volta do Brasil e, possivelmente, na viagem de ida também. ${ }^{56}$

De acordo com os estudiosos da baixela Germain, é provável que esta se mantivesse sob depósito no Tesouro Real, junto com as joias da Coroa e não na mantearia do Palácio da Ajuda. ${ }^{57}$ Em ocasiões muito especiais era retirada com todo o cuidado e transportada com segurança ao local de destino. No retorno ao Tesouro, as peças eram conferidas e novamente guardadas da mesma forma, como indicam os registros sobre os deslocamentos de peças da referida baixela para o banquete ocorrido no Paço da Cidade do Rio de Janeiro, por ocasião das núpcias de D. Pedro I com D. Leopoldina, assim como no almoço oferecido por D. Carlota Joaquina à sua nora, no dia seguinte às bodas, no palácio de São Cristóvão. ${ }^{58}$ Mas não foram apenas as peças da baixela Germain ou da baixela de serviço que circularam de um lado a outro do Império português ou entre os paços da Coroa portuguesa. Artefatos de mesa em prata e também aqueles confeccionados em outros materiais circulavam entre os diferentes palácios reais por motivos diversos, como por exemplo, em caso de divisão de bens por falecimento de um dos membros da Família Real ou para compor os bens já existentes. Neste último caso, a transferência dos objetos poderia ser por tempo indeterminado, ou para atender a uma ocasião específica, como sucedia nas jornadas da Família Real para seus palácios de caça e veraneio.

Salvaterra de Magos, por exemplo, era um palácio medieval que foi melhorado e ampliado por vários monarcas e que teve sua época áurea com D. José I. Famoso por suas coutadas, lá ocorriam festas e caçadas. Os registros da mantearia real indicam que D. João VI para lá se dirigiu algumas vezes e que, para atendê-lo adequadamente, seguiram prata e roupa de mesa. Exemplos desse tipo de deslocamento de artefatos ocorreram em 5 de janeiro de 1822 e em 2 de fevereiro do ano seguinte. Em ambas as ocasiões, foram enviadas da mantearia da Casa Real peças de serviço de mesa em prata. A lista era composta de duas dúzias de talheres, duas colheres de sopa e uma de arroz, três salvas de diferentes
51. Maravall (1997, p. 40).

52. Maravall (1997, p. 40).

53. Segundo Pires, uma carta de João dos Santos, almoxarife do Palácio do Ramalhão, informava à princesa D. Carlota, em 17 de outubro de 1808, que toda a mobília desse palácio havia ido para o Brasil, ao contrário do que sucedera com a de D. João e de outros senhores, que ficaram no cais (1926, p. 312, nota 1); ver também, sobre remessas para o Brasil, IAN/ TT, Mesa Real, caixa 3760 , 29 ago. 1809 apud Jardim (2002, p. 185).

54. Leonor d'Orey esforça-se em localizar onde se encontram, hoje, as diversas peças da baixela. Com base nos recibos das encomendas feitas a François Germain e na relação dos envios das peças a Lisboa por seu artesão, observa-se que os objetos que ficaram no Brasil estão dispersos em coleções particulares ou de museus, em diferentes países (1999b, p. 148-155) Ver também D’Orey (1991).

55. No Brasil do século XVIII, as baixelas em prata lisa, confeccionadas localmente, eram para uso doméstico. Entende-se que seriam mais simples do que a "prata lavrada". Ver sobre o assunto Goulão (1999, p. 135-145).

56. Para Maria do Rosário Jardim, que estudou em detalhes o percurso da baixela Germain desde Lisboa ao Brasil, bem como suas aparições públicas no Rio de Janeiro, no reinado de D. João VI, a prataria da Mantearia (da qual fariam parte as peças do inventário que estamos analisando) foi enviada para a América, posteriormente à partida $\mathrm{da}$ Corte. De acordo com seus estudos, a baixela Germain, guardada junto com outros objetos do Tesouro, teria embarcado na nau na qual 
viajou o então príncipe D. João. Jardim (2002, p. 183, 185, 188, 192).

57. De acordo com Maria do Rosário Jardim, até meados do século XIX não cabia à Mantearia da Casa Real a tutela da baixela Germain e do restante de prata de grande aparato. Ao que parece, a essa seção cabia cuidar da prata destinada ao serviço diário das mesas do Paço. Jardim (2012, p. 1-35).

58. Sobre estes e outros deslocamentos da baixela nas celebrações régias na Corte do Rio de Janeiro, ver Jardim (2002, p. 188-191).

59. Rellação (1822, f. 68); junto com a prata seguiram roupa grossa (12 toalhas, 120 guardanapos e 24 toalhas de água às mãos) e roupa fina ( 48 toalhas terceiras, 24 toalhas de mãos e 216 guardanapos).

60. Rellação (1822, f. 68); junto com a prata seguiram roupa grossa (12 toalhas, 120 guardanapos e 24 toalhas de água às mãos) e roupa fina (48 toalhas terceiras, 24 toalhas de mãos e 216 guardanapos).

61. A coleção de cerâmica do acervo do Palácio Queluz contém peças que integraram serviços de mesa da Casa Real, originárias de diferentes residências régias. Há artefatos de procedências diversas e peças de serviços de jantar, chá, café e chocolate encomendados no período de regência e reinado de D. João VI, entre outros (Ferro; Flores, 2002, p. 20-21). Sobre as peças de decoração e serviço em porcelana, prata e outros materiais importados da Europa e Oriente, ver Correia (2011, p. 168-171).

62. Rellação (1822, folha 70, 7 jun. 1826). tipos, bule, cafeteira e leiteira, além de dois açucareiros, doze colherinhas para o chá e uma para o açúcar, bacia e jarro para água às mãos. ${ }^{59}$ Já em fevereiro de 1823, enviaram-se apenas duas dúzias de talheres de prata e uma colher de tirar sopa. ${ }^{60}$ Mesmo que cada palácio tivesse seu próprio conteúdo de móveis e demais artefatos, as deslocações da corte exigiam grandes movimentações de gentes e de coisas, como cozinheiros, médicos, artistas e também: tapeçarias, roupa de mesa, baixelas, móveis. Muitos desses objetos eram produtos estrangeiros e de consumo de luxo, como os serviços de mesa em porcelana, as peças destinadas à decoração, ou os copos e taças. ${ }^{\circ}$

A documentação da mantearia confirma ainda a informação de que o rei se estabeleceu no Palácio da Bemposta, após o seu retorno do Brasil, mas costumava visitar o Palácio Novo da Ajuda, pois em 1826 os registros desse departamento informam que "foi entregue para o serviço de Sua Majestade e Altezas, para quando cá vem, o trem seguinte: uma salva de prata, uma copa de vinho para El Rei, três copos de água de Suas Altezas, treze pratos azuis, uma toalha de mãos, dois guardanapos finos, dois ditos grosso". 62

Documentos que se seguem ao inventário da prata analisado indicam ainda que, do lote de objetos enviados do Rio de Janeiro, foram retiradas peças para "o real serviço da rainha, nossa senhora qe deos Guarde" e entregues contrarrecibo a um servidor da Sua mantearia, em 13 de outubro de 1821 . Ou seja, a partilha das peças ocorreu três dias antes de darem entrada no Pátio da Ajuda. Esse tipo de informação sugere se tratar de um inventário realizado para controle, haja vista serem peças de prata e de valor, mas também uma prática cotidiana de responsabilidade dos oficiais desse setor da Casa Real, que deveriam acusar a movimentação de tais objetos.

O inventário indica que, mesmo retiradas as peças para o serviço de D. Carlota (possivelmente enviadas para o Palácio de Queluz onde ela viveu, separada do monarca após a volta do Brasil, e veio a falecer em 1830), o conjunto permaneceu coeso em grande parte, especialmente as travessas e os pratos de comer, peças fundamentais em qualquer baixela e especialmente importantes no serviço à francesa, que necessitava de um grande número de objetos do mesmo tipo, conforme já mencionado.

Os deslocamentos de artefatos de um palácio a outro e, inclusive, entre os diferentes domínios do Império português - sendo, em alguns casos, notórios símbolos da realeza, como livros, coches, móveis, joias, cerâmicas e prataria de mesa-evidenciam a relação intensa dos proprietários com seus objetos. Estes recebiam, muitas vezes, suas insígnias, como marcas-d'água e ex libris, no caso dos livros, ou monogramas e armas da Coroa, como não raro sucedia com copos, pratos, xícaras, talheres e roupa de mesa. Objetos, enfim, que conferiam ou confirmavam identidades.

Embora a historiografia sobre o período joanino no Brasil tenha tornado célebres as cenas de desolação em Lisboa, tanto daqueles que partiam quanto dos que permaneciam em terra, bem como se esforçado em calcular o número de 
pessoas que acompanharam a Família Real na viagem, menor atenção tem sido dada às coisas embarcadas. ${ }^{63}$ As crônicas e memórias da partida, porém, não pouparam relatos sobre caixotes abandonados em terra, como se os objetos neles contidos não fossem importantes, tendo sido tratados com displicência, em meio ao caos instalado na cidade. Nas palavras do marquês de Fronteira e Alorna, por exemplo, "as bagagens da corte, expostas ao tempo e quase abandonadas ocupavam desde a rua da Junqueira até o Cais, e as carruagens não puderam entrar no Largo de Belém", pois este, segundo o mesmo observador, encontrava-se congestionado com os regimentos que faziam a guarda, com a multidão de expectadores e com o excesso de bagagens. ${ }^{64}$

Os documentos sobre as ordens do rei relativas à preparação da viagem, aliados aos estudos sobre a Biblioteca Real no Rio de Janeiro, bem como com aqueles dedicados à baixela Germain, sugerem uma postura bem diferente em relação aos bens materiais. $\bigcirc$ que desponta é um profundo interesse com os objetos da Família Real, quer fosse por sua preciosidade, quer fosse devido ao significado político que continham.

Afinal, se a ideia de transferir a Corte para os domínios americanos era salvar a Monarquia, então seus símbolos materiais deveriam acompanhá-la. Como bem observou Kirsten Schultz, "ainda que Portugal continuasse a ser um ponto de referência, em última análise era a corte no Novo Mundo que parecia possibilitar a renovação nacional. Trágica ou heroicamente, o exílio real redefiniu a monarquia imperial como americana". 65 Em vista disso, tais objetos não poderiam jamais ter permanecido em Lisboa à mercê do saque dos soldados estrangeiros. Transportá-los para o Brasil era imperativo. Afinal, sua ausência retiraria da estadia da Corte nos trópicos grande parte do brilho e dos meios necessários à sua celebração.

A exposição pública de objetos de luxo, assim como sua preservação junto aos membros da Família Real (tanto de D. João, na viagem e em sua permanência no Brasil, como de seu filho e sucessor, após a partida do reil, estimula repensarmos a imagem de pobreza material da Corte no Rio de Janeiro, algo que estudos sobre o período joanino têm, recorrentemente, afirmado há mais de cem anos. ${ }^{60}$ Aliada a essa imagem de "utensilagem precária" nos diferentes setores da Corte (mesa, transporte, vestuário), bem como de falta crônica de servidores e demais recursos, 67 somam-se aquelas referentes ao aspecto absolutamente impróprio da acanhada e pobre cidade colonial que se viu despreparada para acolher uma corte europeia. ${ }^{68}$

Os registros referentes aos primeiros tempos da chegada da Família Real, tanto aqueles dos viajantes estrangeiros, como dos assessores diretos do príncipe regente, mencionam não só os desconfortos físicos e o sentimento de exílio que tomaram conta dos recém-chegados, mas especialmente a necessidade de transformar a cidade para que pudesse honrar seu novo estatuto de sede do Império português. A nosso ver, é como se a precariedade do espaço físico, vivenciada pelos contemporâneos, se estendesse na historiografia, a outros espaços e domínios, não importando a quantidade imensa de joias e de objetos de luxo que cruzaram
63. Sobre a população a bordo e sobre a travessia da Corte para o Brasil, ver Malerba (2011, p. 47-62), Light (2008, p. 107).

64. Fronteira (1928, p. 31-32) apud Castro (2016, p. 27).

65. Schultz (2008, p. 111).

66. Além da obra clássica de Lima (2006), publicada originalmente em 1908, ver Malerba (2000, p. 180-183), cuja análise enfatiza a simplicidade que imperava na Casa Real.

67. Malerba (2000, p. $180-$ 183). Nos livros didáticos e paradidáticos e mesmo no cinema, à imagem de pobreza da Corte portuguesa nos trópicos aliaram-se visões caricatas da personalidade e da vida doméstica dos monarcas, como se sua presença no Novo Mundo fizesse parte de um inusitado paradoxo: a presença de uma nobreza europeia branca em uma cidade, na América, com maioria escrava negra. Ver, por exemplo, Gomes (2008); Carlota (1995)

68. Imagens fortemente presentes nos relatos dos contemporâneos foram analisadas de forma inovadora por estudos recentes dedicados à urbanização do Rio de Janeiro e à presença da Corte na cidade. Ver, entre outros, Schultz (2008, p. 153-168), Carvalho (2008, p. 96-98), Castro (2013, p. 78-98). 
69. Entre os viajantes que descreveram em detalhes as transformações da cidade do Rio de Janeiro nos anos 1810, destaca-se Luccok (1975, p. 24-28 e 162-168). Sobre o desencantamento dos recém-chegados com a cidade do Rio de Janeiro, ver, por exemplo, Marrocos (2008, p. 160).

70. Para uma análise da ideia de D. Rodrigo de Souza Coutinho sobre um novo e poderoso império a partir da América, ver Lyra (1994).

71. Dias (2009, p. 19).

72. As listas dos almoxarifes contendo artefatos de uso cotidiano e de luxo enviados e depois retornados do Brasil, as ordens do regente para recuperar e cuidar de sua propriedade no Reino, assim como correspondências trocadas com os responsáveis pelos palácios reais em Portugal, indicam um interesse e um cuidado pelas coisas necessárias à vida da Corte.

73. Sobre a dimensão política dos objetos de prata nas cortes absolutistas, especialmente os móveis, ver Liebgott; Saule (2007, p. 24).

74. Liebgott; Saule (2007, p. 24).
- Atlântico, pertencentes não só à Família Real, mas também à alta nobreza portuguesa que acompanhou D. João em sua fuga para o Brasil. 69

Como em uma pintura, na qual a paisagem participa e reforça a imagem principal, a presença de artefatos de mesa luxuosos, assim como as regras de etiqueta a eles relacionadas, não só integra o cenário da modernização do Rio de Janeiro no período, como no fundo dá sentido a uma Corte que optou por permanecer na América - mesmo após o fim do conflito na Europa -, transformando sua capital no centro de um "novo e poderoso império", o qual acabou por inverter a antiga ordem de dominação Metrópole/Colônia. ${ }^{70}$ Como observou Maria Odila da Silva Dias, "a vinda da Corte com o enraizamento do Estado português no Centro-Sul daria início à transformação da colônia em metrópole interiorizada" ${ }^{71}$

\section{Considerações finais}

A ideia de circulação de bens, contida nas ordens de D. João VI para trazer para o Rio de Janeiro, mandar buscar em Portugal e levar de volta coisas de uso pessoal e doméstico, em vez de indicar ausência de objetos e, consequentemente, uma corte pobre e desfalcada de bens materiais na América, pode sugerir uma relação intensa entre as coisas e seus proprietários, quer em termos de posse, devido ao valor monetário contido nas mesmas, quer em decorrência dos valores sociais que em tais bens foram investidos. Daí, inclusive, a preocupação da Família Real com os objetos que ficaram em Portugal sob os cuidados dos almoxarifes dos seus palácios, bem como com aqueles objetos que foram escondidos, a pedido do rei, antes da chegada das tropas francesas. Ao que parece, os membros da realeza portuguesa não desejavam trazer para sua nova morada qualquer objeto, mas sim uma série de coisas que por motivos diversos eram tão significativas na construção de sua identidade, ou na vida de Corte, que foram embarcadas às pressas antes que os franceses pudessem se apossar delas. ${ }^{72}$ É o caso da prataria de aparato, incluindo os artefatos de mesa destinados à convivialidade doméstica, mas fundamentalmente à celebração e à ostentação de riqueza e poder.

A posse e o uso de baixelas de prata nas refeições festivas eram praticamente uma imposição do cerimonial de Corte em grande parte dos países europeus. Sua exposição nos aparadores era não só um gesto de moda como uma manifestação de prestígio garantida em Portugal e seus domínios por lei a alguns poucos privilegiados. As baixelas de aparato confeccionadas em prata lavrada adquiriam também uma dimensão política. ${ }^{73}$ Feitas para impressionar, dadas a quantidade de prata e as dimensões dos artefatos (pesadíssimos), eram geralmente de excelente qualidade artística. Daí serem guardadas com o Tesouro da Coroa. Frequentemente gravadas com emblemas heráldicos, as peças de prata eram muitas vezes decoradas com figuras mitológicas e relevos históricos alusivos às circunstâncias e especificidades da Casa que as possuía. ${ }^{74}$ Tais objetos evocavam, 
portanto, a grandiosidade de seus proprietários e auxiliavam na avaliação das variações sociais e do grau de prestígio das famílias. Como esclareceu Norbert Elias ao analisar a sociedade de corte,

a regulamentação minuciosa da etiqueta, do cerimonial, do gosto, do modo de vestir e mesmo do modo de falar, não visava apenas a representação exterior, a conquista de um estatuto mais elevado e de maior poder, a segregação face ao comum dos mortais; marcava mentalmente as distâncias que separavam uns dos outros, no plano interno, os membros da sociedade. ${ }^{75}$

Já as baixelas de prata lisa, embora sem a suntuosidade das baixelas de aparato, também sublinhavam a identidade social elevada de seus proprietários, servindo de signo exterior de riqueza, além de representarem um patrimônio econômico. Estas foram geralmente vistas como uma reserva financeira para o futuro, sendo encomendadas para serem transmitidas na forma de herança e de dote. ${ }^{76}$ A prataria de mesa permitiu, assim, que através dela fossem estabelecidas relações entre Casas principescas e entre delegações diplomáticas. ${ }^{77}$

A presença dos objetos de prata, associada aos ambientes decorados com revestimentos de seda nas paredes e à vidraria de mesa, criava um efeito que encantava aqueles que participavam dos banquetes. ${ }^{78}$ Ao luxo das baixelas somavam-se a abundância e o requinte dos alimentos, dado que causava grande efeito nos observadores. Como disse Maravall, referindo-se à época moderna, mais especificamente ao Barroco, "o valor da eficácia dos recursos visuais é incontestado na época". Para ele, a disputa da superioridade entre o olho e o ouvido para a comunicação do saber tinha um "fundo medieval". Mas o homem moderno tornouse "adepto da primeira via, ou seja, da via do olho". 79

A suntuosidade dos serviços de mesa em prata evocava, portanto, a grandiosidade dos anfitriões e encorajava os convivas a vivenciarem a extravagância de toda essa riqueza, assim como a magnificência do monarca. Em Lisboa ou no Rio de Janeiro, esse era um espetáculo do qual a Corte de D. João VI não poderia se furtar e que justifica plenamente 0 ir e vir desses objetos acompanhando a Família Real em suas duas travessias do Atlântico. A imagem que nos oferecem, certamente, está longe de uma corte picaresca nos trópicos.
75. Elias (1987, p. 86).

76. Deve-se lembrar que os objetos confeccionados em prata podem sempre ser refundidos, a fim de reaver seu valor monetário, como enfatizou Ottomeyer (2007, p. 230).

77. Ottomeyer (2007, p. 229).

78. Na Introdução ao livro Quand Versailles etait meublé d'argent, Niels-Knud Liebgott e Beatrix Saule recriam para o leitor, de forma harmoniosa, o ambiente no qual móveis e objetos de prata se tornaram, desde o século XVII, não só uma imposição da representação do poder dos monarcas, mas também uma demonstração de gosto e um atestado de riqueza e tesouro. Liebgott; Saule (2007, p. 23-25).

79. Maravall (1997, p. 391). 


\section{REFERÊNCIAS}

FONTES MANUSCRITAS

Arquivo Nacional da Torre do Tombo (ANTT)

INVENTARIO da Prata, e Roupa e mais trem pertencente à Mantearia, de Sua Magestade, q veio do Ryo de Janeiro. 1821. Fundo Casa Real, Cx. 2986, f. 60 e ss.

RELLAÇÃO da Prata que foi pa. Salvaterra pr Ordem de o Sr João Lourenço de Andrade em 5 de janeiro de 1822. Fundo da Casa Real, Cx. 2986.

\section{FONTES IMPRESSAS}

BLUTEAU, Raphael. Vocabulario Portuguez \& Latino. Coimbra: Colégio das Artes da Companhia de Jesus, 1712-1728, 8 v. Disponível em: <http://dicionarios.bbm.usp.br/pt-br/ dicionario/1/mantieiria>. Acesso em: 20 jan. 2017.

LUCCOCK, John. Notas sobre o Rio de Janeiro e partes meridionais do Brasil. Trad. Milton da Silva Rodrigues. São Paulo; Belo Horizonte: Editora da Universidade de São Paulo; Editora Itatiaia, 1975.

MARROCOS, Luis Joaquim dos Santos. Cartas do Rio de Janeiro: 1811-1821. Lisboa: BNP, 2008.

PRAGMÁTICA de D. João V (1749) em que se regula a moderação dos adornos e se proíbe o luxo, e excesso dos trajes, carruagens, moveis e lutos, o uso ds espadas a pessoas de baixa condição, e outros diversos abusos, que necessitavam de reforma. Appendix das Leys Extravagantes. Lisboa: Mosteiro de São Vicente de Fora, 1760, p. 19-24.

SANTOS, Luiz Gonçalves dos. Memórias para servir ao Reino do Brasil. Lisboa: Impressão Régia, 1825. (V. 1 e 2).

LIVROS, ARTIGOS E TESES

ALGRANTI, Leila Mezan. Notas sobre a mesa da casa real portuguesa no reinado de D. José I. In : SÁ, Isabel dos Guimarães; GARCIA, Maximo Fernández (Org.). Portas Adentro: comer, vestir, habitar (séculos XVI-XIX). Coimbra, Valladolid: Universidade de Coimbra, Universidad de Valladolid, 2010, p. 87-113. 
Rituais e protocolos das mesas reais no século XVIII . In : BUESCU, Ana Isabel; FELISMINO, Davi (Org.). A Mesa dos Reis de Portugal. Lisboa: Círculo dos Leitores, 2011, p. 244-259.

Alimentação e cultura material no Rio de Janeiro dos vice-reis: diversidade de fontes e possibilidades de abordagens. Varia Historia. Belo Horizonte, v. 32, n. 58, p. 21-51, 2016. Disponível em: < http://www.scielo.br/scielo.php?script=sci_arttext\&pid=S0104-87752016000100021\&lng=en\& nrm=iso\&tlng=pt>. Acesso em: 17 jan. 2017.

ANDRADE, Santiago Silva de. Uma casa nos trópicos: A casa Real portuguesa no Rio de Janeiro (1808-1821). In: CARDOSO, José Luís; MONTEIRO, Nuno Gonçalo; SERRÃO, José Vicente (eds.). Portugal, Brasil e a Europa napoleônica. Lisboa: Imprensa de Ciências Sociais, 2010.

ARMINJON, Catherine; SAULE, Béatrix. Tables Royales et Festin de cour en Europe (16611789). In: Actes du Colloque international, Versailles, 1994. Paris: La Documentation Française; École du Louvre, 2004.

BOURDIEU, Pierre. O poder simbólico. Trad. Fernando Tomaz. Lisboa: Difel, 1989.

BRAGA, Isabel Drumond. Dos tachos e panelas aos açucareiros e bules. Recipientes para confeccionar e servir alimentos em Portugal na época moderna. História: Questões e Debates, Curitiba: UFPR, no 54, p. 71-101, jan/jun 2011.

BUESCU, Ana Isabel; FELISMINO, Davi (Org.). A mesa dos reis de Portugal. Lisboa: Círculo de Leitores, 2011.

CARVAlHO, Marieta Pinheiro de. Uma ideia ilustrada de cidade: as transformações urbanas do Rio de Janeiro de D. João VI. Rio de Janeiro: Editora Odisseia, 2008.

CASTRO, Giovanna Milanez de. Serviço e celebração nos trópicos: a Casa Real portuguesa no Rio de Janeiro do período joanino. Campinas, 2016. Dissertação (Mestrado) - Departamento de História, Unicamp.

Palco da realeza - as transformações no espaço urbano e nas práticas sociais do Rio de Janeiro joanino (1808-1821), Campinas: Gráfica do IFCH/Unicamp, 2013, p. 78-98. (Coleção Monografia IFCH, 22).

CAMPORESI, Piero. Hedonismo e Exotismo: a arte de viver na época das Luzes. Trad. Gilson César Cardoso de Souza. São Paulo: Editora da Unesp, 1996.

CORREIA, Cristina Neiva. Deslumbramento, profusão e ordem. Aspectos decorativos da mesa real em finais do século XVIII In: BUESCU, Ana Isabel; FELISMINO, Davi (Org.). A Mesa dos Reis de Portugal. Lisboa: Círculo de Leitores, 2011, p. 166-186.

Desserts e arte efémera (1777-1800). In : GODINHO, Isabel da Silveira. A Baixela de sua majestade fidelíssima: uma obra de François Thomas Germain. Lisboa: Instituto Português do Patrimônio Arquitetônico; Palácio Nacional da Ajuda, 2002, p. 144-181.

DIAS, Maria Odila da Silva. A Interiorização da metrópole e outros estudos. 2. ed. São Paulo: Editora Alameda, 2009, p. 7-37. 
D'OREY, Leonor. A Baixela da Coroa Portuguesa. Lisboa: Edições INAPA, 1991.

Apresentação. Actas do Simpósio Internacional - Mesas Reais Europeias. Lisboa: Instituto Português de Museus, 1999a, p. 6-8.

Dispersed objects from the Portuguese Royal and Princely Silver Services composing a Puzzle. In: Mesas Reais Europeias - encomendas e ofertas. Lisboa: Museu de Arte Antiga; Instituto Português de Museus, 1999b, p.148-155.

DUARTE, Marco Daniel. "Sacrum Convivium" - Formas e conteúdos da ceia do rei de Portugal na Idade Média a partir das figurações icônicas. De Arte. León, n. 4, p. 89-120, 2005. Disponível em <http://revpubli.unileon.es/index.php/dearte/article/view/1572>. Acesso em 25 set 2016.

ELIAS, Norbert. A Sociedade de Corte. Trad. Ana Maria Alves. Lisboa: [s.n.], 1987.

FERRO, Inês; FLORES, Ana (Coord.). O Palácio de Queluz e seu Acervo. Lisboa: Impressão Rainho \& Neves; Ministério da Cultura, 2002.

FLANDRIN, Jean Louis; MONTANARI, Massimo (Dir.). História da Alimentação. Trad. Luciano Vieira Machado e Guilherme João de Freitas Teixeira. São Paulo: Editora Estação Liberdade, 1997.

L'Ordre des mets. Paris: Editions Odile Jacob, 2002.

FONSECA, Edson Nery; FREYRE, Gilberto. China Tropical. Brasília; São Paulo: Editora da UNB; Imprensa Oficial do Estado de São Paulo, 2003.

FRONTEIRA, $7^{\circ}$ Marquês de. Memórias do Marquês de Fronteira e d'Alorna D. José Trazimundo Mascarenhas Barreto ditadas por ele próprio em 1861. Coimbra: Imprensa da Universidade, 1928.

GOMES, Laurentino. 1808. São Paulo: Editora Globo, 2008.

GOULÃO, Maria José. A Arte da prataria no Brasil e no rio da Prata no período colonial: estudo comparativo. In: Anales del Instituto de Insvestigaciones Estéticas, v. 21, n ${ }^{\circ} 74, \mathrm{p}$. 135-145, 1999.

JARDIM, Maria do Rosário. A baixela Germain ao serviço da corte no reinado de D. Maria I. In: Artigos em Linha $n^{\circ}$ 6. Lisboa: Palácio Nacional da Ajuda, fev. 2012. Disponível em: $<$ http://pnajuda.imc-ip.pt/pt-PT/estudos/artigosemlinha/ContentDetail.aspx?id=613>. Acesso em: 25 set. 2016.

O Brasil na história da baixela. In: GODINHO, Isabel da Silveira. A Baixela de sua majestade fidelíssima: uma obra de François Thomas Germain. Lisboa: Instituto Português do Patrimônio Arquitetônico; Palácio Nacional da Ajuda, 2002, p. 181-209.

LIEBGOTT, Niels-Knud; SAULE, Beatrix. Introduction. In: ARMINJON, Catherine (coord.). Quand Versailles était meublé d'argent. Paris: Editions de la Réunion des Musées Nationaux, 2007, p. 23-25. 
LIGHT, Kenneth. A viagem marítima da família real: a transferência da corte portuguesa para o Brasil. Rio de Janeiro: Jorge Zahar Editor, 2008.

LIMA, Manoel de Oliveira. D. João VI no Brasil. Rio de Janeiro: Topbooks, 2006.

LYRA, Maria de Lourdes Vian. A Utopia do poderoso império, Portugal e o Brasil: bastidores da política - 1798-1822. Rio de Janeiro: Sete Letras, 1994.

MALERBA, Jurandir. A corte no exílio: civilização e poder no Brasil às vésperas da independência (1808-1821). São Paulo: Companhia das Letras, 2000.

. Sobre o tamanho da comitiva. Revista Acervo, Rio de Janeiro: Arquivo Nacional, v. 21, n. 1, p. 47-62, 2011.

MARAVALL, José Antônio. A Cultura do Barroco - análise de uma estrutura histórica. Trad. Silvana Garcia. São Paulo: Edusp/Imprensa Oficial, 1997.

MONTEIRO, Nuno Gonçalo. Cozinha, família e cavalariças: padrões de consumo da aristocracia de corte em Portugal no século XVIII. In: BUESCU, Ana Isabel; FELISMINO, Davi (Org.). $A$ Mesa dos Reis de Portugal. Lisboa: Círculo de Leitores, 2011, p. 100-114.

OTTOMEYER, Hans. L'argent: vertus, mythes et symboles. In: ARMINJON, Catherine (coord.). Quand Versailles etait meublé d'argent. Paris: Editions de la Réunion des Musées Nationaux, 2007, p. 229-231.

PEREIRA, Ana Marques. Mesa Real - dinastia de Bragança. Lisboa: Edições Inapa, 2007.

PÉREZ-SAMPER, Maria de los Angeles. Fiesta y alimentación en la España moderna: el banquete como imagen festiva de abundancia y refinamiento. Historia Moderna, Espacio, Tiempo y Forma. Madrid, serie IV, t. 10, p. 53-98, 1997.

PIRES, Antonio Caldeira. História do Palácio de Queluz. Coimbra: Imprensa da Universidade, 1926, vols. 1 e 2 .

RIGAUD, Lucas. Cozinheiro Moderno ou Nova Arte de Cozinha. Sintra: Colares Editores, 1999.

ROSA, Mercedes. Ourivesaria baiana colonial: os ourives e suas obras. [S.1.]: [s.n.], 2007, p. 403-404. Disponível em: <ler.letras.up.pt/uploads/ficheiros/6164.pdf>. Acesso em: 25 set. 2016.

SANTOS, Francisco Marques dos. A Prata no Brasil. In: MACHADO, Paulo Affonso de Carvalho. Antiguidades do Brasil. Disponível em: <www.areliquia.com.br/01\%20-\%20A\%20Prata\%20 no\%20Brasil.doc>. Acesso em: 25 set. 2016.

SCHULTZ, Kirsten. Versalhes Tropical,Rio de Janeiro, Civilização Brasileira, 2008

SILVA, Nuno Vassallo e. Encomenda, uso e colecionismo de ourivesaria no século XVIII: a mantearia da Casa de Aveiro em 1752. Revista de História da Arte, Lisboa: Faculdade de Ciências Sociais e Humanas, ${ }^{\circ}$ 9, p. 69-91, 2012. 
SOUSA, Gonçalo de Vasconcelos e. Artes da Mesa em Portugal - do século XVIII ao XXI. Porto: Livraria Civilização Editora, 2002.

STRONG, Roy. Banquete: uma história ilustrada da culinária, dos costumes e da fartura à mesa. Trad. Sergio Goes de Paula. Rio de Janeiro: Jorge Zahar Editor, 2004.

\section{FILMES}

CARLOTA Joaquina, Princesa do Brasil. Direção de Carla Camurati. [S.1]: Copacabana Filmes, 1995.

Artigo apresentado em 29/01/2017. Aprovado em 22/03/2017. 